\title{
NON-SURGICAL MANAGEMENT OF FRACTURED ORTHODONTIC MINI- IMPLANT- A CASE REPORT
}

\author{
SAMEER AHMAD MALIK ${ }^{\mathrm{a} 1}$, CHANDRASHEKHAR HALLOLI ${ }^{\mathrm{b}}$ AND S. VANDANA $^{\mathrm{c}}$ \\ ${ }^{\mathrm{abc}}$ Department Orthodontics and Dentofacial Orthopedics, AECS Maaruti College of Dental Sciences and Research Centre, Bangalore, \\ India
}

\begin{abstract}
Orthodontic temporary anchorage devices allow tooth movements previously thought to be impossible or difficult. Even though extensive literature exists on use of temporary anchorage devices, their individual failure causes have been only recently focused upon, especially implant fracture. The following case report describes management of fractured orthodontic mini-implant without a surgical intervention.
\end{abstract}

KEYWORDS: Orthodontic mini-implant, surgical

A 23-year-old male patient was referred to the Department of orthodontics and diagnosed with a class 1 molar relationship with labial crowding in upper and lower arches. He had a palatally in standing lateral in the first quadrant with an overriding canine. It was decided to use TAD for retraction of the particular canine while the levelling and aligning was done simultaneously. As per the anchorage requirements. A $1.5 \times 8 \mathrm{~mm}$ Titanium implant (S.K Surgical, Pune, India) was used. During the placement of the implant in $15-16$ regions it fractured with $7 \mathrm{~mm}$ inside the bone (Figure 1). The probable cause of fracture was thick cortication of bone and possibly the inability of the implant to withstand the torque. A radiograph was taken to determine the exact position of the implant and to gauge its proximity to nearby structures. It was decided to remove the implant non surgically with a careful use of a sharp edges of deboning plier. A written informed consent was obtained from the patient. After obtaining adequate anesthesia the gingival tissues around the implant was released and slightly gouged with a sharp probe to allow enough space for the deboning plier beaks to engage the fractured implant at least two threads down from its fractured surface. The fractured TAD was held with the beaks of a deboning plier and the plier was carefully rotated in anticlockwise direction in a "watch winding motion". After approximately 6 full clock turns the TAD was retrieved (Figure 2). During this process it was made sure that the TAD doesn't slip out or gets released from the grip of the beaks. The exposed surface was covered with a COEPAK ${ }^{\mathrm{TM}}$ AUTOMIX Surgical Dressing. Postoperative antibiotics and analgesics were prescribed. Pack removal was done after a week following uneventful healing. The site was left alone another 4 weeks to heal, after which another implant was placed in the same site using a pilot drill this time.

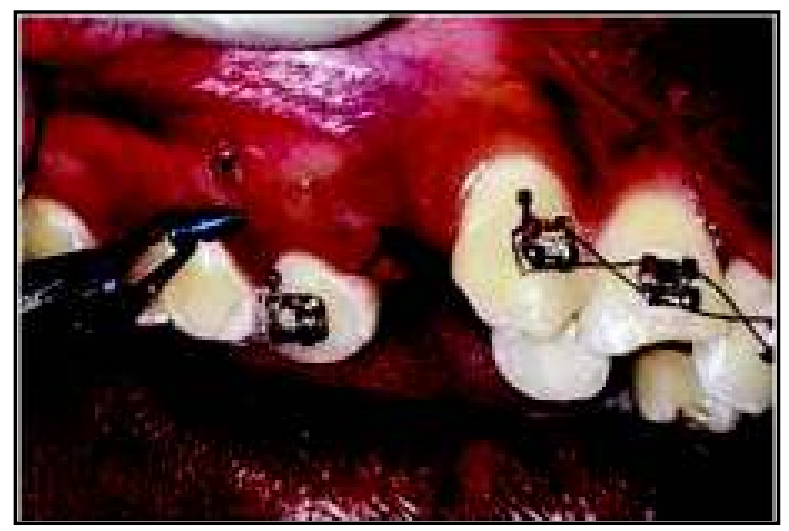

Figure 1: Fracture of mini implant while placing between 15 and 16

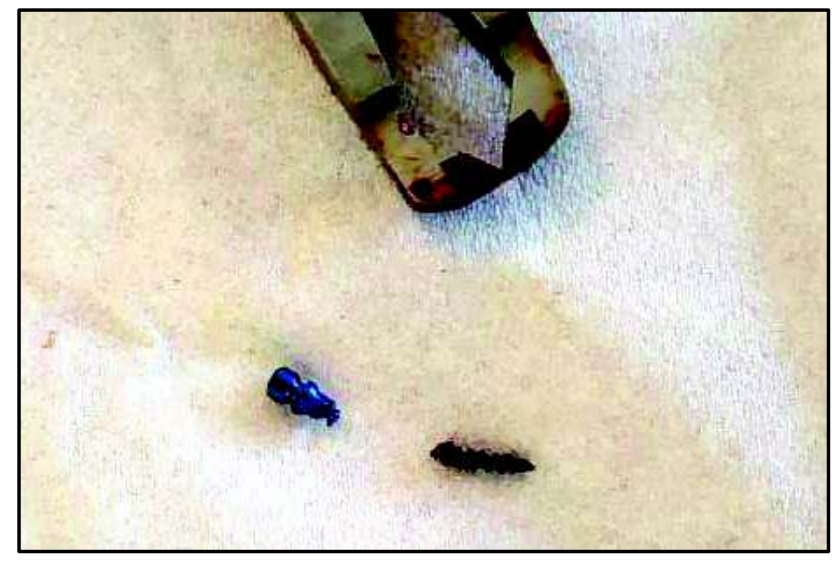

Figure 2: Retrieved fractured mini implant - non surgically 


\section{DISCUSSION}

The idea of absolute anchorage is a solution for clinicians who seek to move teeth without unwanted sequel (Creekmore and Eklund, 1983). Orthodontic mini- implant or temporary anchorage devices (TAD) when used as either direct or indirect skeletal anchors can provide absolute anchorage for a multitude of tooth movements. TADs have opened a new vista in orthodontics, allowing tooth movements previously thought to be difficult or impossible. They provide a fixed point for the application of forces to move teeth in the desired position. They can be placed in different positions in the mouth and can be customized as per patient's need. Clinicians continue to search methods that aid in accomplishing desired treatment objectives without relying on patient compliance. TADs appear to fulfill these objectives (Baumgaertel et al., 2008).

Though helpful, TADs are not without disadvantages. The ease of use of TAD has led to their injudicious use. Some problems associated are inadequate bone for placement, risk of infection, loss of primary or secondary stability, soft tissue impingement, and fracture (Park. et al., 2006, Cheng et al., 2004). These problems can be minimized by analyzing implant material, dimensions and bone - soft tissue biology. Insertion methods of TADs may be categorized as either drill-free or non-drill-free, depending on the thread design. Drill-free feature a cutting tip which does not require that a pilot hole be created before insertion, while non-drill-free designs commonly require a soft-tissue punch and a pilot hole to be drilled in bone before placement. Factors that influence the amount of torque exerted during insertion: bone, quality, pilot hole size, thread design, and insertion methodology (Ansell and Scales, 1968). Suzuki et al., concluded that incidence of fracture and torque values were directly proportional (Suzuki and Suzuki, 2011). Barros et al., 2011 concluded that TADs with diameter less than $1.5 \mathrm{~mm}$ are more prone to fracture. Butcher et al., 2005 reported an average 4\% incidence of fracture while placement of TADs. Mischkowski et al., 2008 reported 9.5\% incidence of fracture at insertion torques ranging from $52-56 \mathrm{Ncm}$. A few precautions can be exercised to avoid fracture of TAD (1) assessment of bone density utilizing radiographs or CBCT scan, which are used for treatment planning, (2) use of pilot drills when tough resistance is experienced during placement, use of torque measuring devices while placement of TAD. Optimal range of torque is $5-10 \mathrm{Ncm}$, values exceeding $10 \mathrm{Ncm}$ may result in fracture of TAD (Motoyoshi et al., 2006). Once the TAD fractures, there are only limited options at hand. The decision whether or not to retrieve the fractured TAD depends on site and location of the fracture and patients consent. Periodic evaluation is needed when it is decided not to retrieve the TAD. If the TAD stump is visible, a slot can be prepared to engage a screw driver and unscrew it. And if it is not visible, a carbide or trephine bur to facilitate the removal surgically is usually attempted. However initially attempting it to remove with the help of beaks of a deboning plier or a modified instrument having similar beaks but a locking mechanism for its handle, could provide a possible more conservative alternative, as described in the case report.

\section{CONCLUSION}

There exists extensive literature on TADs but their failures especially fracture has only been recently focused upon. There are quite a few documented case reports on it. The following case report describes successful nonsurgical management of TAD fracture. TAD fractures although is a rare clinical possibility and has to be managed wisely. A sound knowledge of biological and mechanical aspects of TADs would be instrumental in avoiding complications.

\section{REFERENCES}

Ansell R.H. and Scales J.T., 1968. A study of some factors which affect the strength of screws and their insertion and holding power in bone. J. Biomech., 1(4):279-302.

Barros S.E., Janson G., Chiqueto K., Garib D.G. and Janson M., 2011. Effect of mini-implant diameter on fracture risk and self-drilling efficacy. Am. J. Orthod Dentofacial Orthop., 140(4):181-92.

Baumgaertel S., Razavi M.R. and Hans M.G., 2008. Miniimplant anchorage for the orthodontic practitioner. Am. J. Orthod Dentofacial Orthop., 133(4):621-27.

Büchter A., Wiechmann D. and Koerdt S., 2005. Loadrelated implant reaction of mini- implants used for orthodontic anchorage. Clin. Oral Implants Res., 16(4):473- 79.

Cheng S.J., Tseng I.Y., Lee J.J. and Kok S.H., 2004. A prospective study of the risk factors associated with failure of mini-implants used for orthodontic 
MALIK ET. AL.: NON-SURGICAL MANAGEMENT OF FRACTURED ORTHODONTIC MINI- IMPLANT...

anchorage. Int. J. Oral Maxillofac Implants, 19(1):100-06.

Creekmore T.D. and Eklund M.K., 1983. The possibility of skeletal anchorage. J. Clin. Orthod., 17(4):266-69.

Creekmore T.D. and Eklund M.K., 1983. The possibility of skeletal anchorage. J. Clin. Orthod., 17(4):266-69.

Mischkowski R.A., Kneuertz P., Florvaag B., Lazar F., Koebke J. and Zöller J.E., 2008. Biomechanical comparison of four different miniscrew types for skeletal anchorage in the mandibulo-maxillary area. Int. J. Oral and Maxillofac Surg., 37(10):94854.
Motoyoshi M., Hirabayashi M., Uemura M. and Shimizu N., 2006. Recommended placement torque when tightening an orthodontic mini-implant. Clin Oral Implants Res., 17(1):109-14.

Park H.S., Jeong S.H. and Kwon O.W., 2006. Factors affecting the clinical success of screw implants used as orthodontic anchorage. Am. J. Orthod. Dentofacial Orthop., 130(1):18-25.

Suzuki E.Y. and Suzuki B., 2011. Placement and removal torque values of orthodontic miniscrew implants. Am. J. Orthod. Dentofacial Orthop., 139(5):66978. 